\title{
Distal Metatarsal Osteotomy for Correction of Hallux Valgus
}

\author{
${ }^{*}$ Ricardo Monreal ${ }^{1}$, Enrique Faedo ${ }^{1}$ and Eilen Monreal ${ }^{2}$ \\ ${ }^{1}$ Centro Médico MEDEX, República de Panamá 3065 2do piso, San Isidro-Lima, Peru \\ ${ }^{2}$ School of Medicine, Ricardo Palma University, Lima, Peru
}

Submission: March 18, 2017; Published: March 27, 2017

*Corresponding author: Ricardo Monreal, MD, Centro Médico MEDEX, República de Panamá 3065 2do piso, San Isidro-Lima, Peru, Email: rmonreal59@yahoo.es

\section{Abstract}

Objective: To evaluate the experience acquired in hallux valgus correction with percutaneous distal metatarsal osteotomy.

Material and Methods: Between January 2012 and July 2016, distal osteotomy of the first metatarsal with lateral displacement has been used in the treatment of 10 patients with hallux valgus. Five patients had bilateral operation done, making up a total of 15 feet. The clinical evaluation of results after surgery using the American Orthopaedic Foot and Ankle Society (AOFAS) scale, the intermetatarsal angle and the hallux valgus angle were also recorded.

Results: All patients reported the disappearance or reduction of pain over the first metatarsal (MT) heads after the operation. A mean improvement of total score from 56.06 points to 90.3 points was achieved in the 15 feet operated. Except one foot with fair result, all the rest of the patients (93.3\%) had excellent to good to excellent result. There were no instances of nonunion, malunion, avascular necrosis of the metatarsal head, or recurrence of hallux valgus.

Conclusion: The distal metatarsal osteotomy and lateral displacement with K-wire stabilization offered a reliable, reproducible, simple, safe, and cost-effective way of treating hallux valgus deformity.

Keywords: Hallux Valgus; Metatarsal Osteotomy; Bunion; Intermetatarsal Angle; Hallux Valgus Angle

\section{Introduction}

Hallux valgus is the most common deformity and disabling condition of the big toe. It was first mentioned by Carl Hueter in 1870 characterized as a combined deformity with a malpositioning in the first metatarsophalangeal (MTP) joint with lateral deviation of the great toe and medial deviation of the first metatarsal bone [1].

Different methods of operation have been described for the correction of hallux valgus, and the continued development of new techniques would suggest that previous techniques are not completely successful [2]. Distal first metatarsal osteotomies traditionally have been indicated for correction of mild-tomoderate hallux valguswhile moderate-to-severe hallux valgus deformities were usually treated with either a proximal metatarsal osteotomy or a metatarso-cuneiform arthrodesis combined with a distal soft tissue procedure [3]. Distal first metatarsal osteotomy should not be considered for hallux valgus deformities with an intermetatarsal angle (IMA) exceeding $16^{\circ}$; however, theoretically correction of IMA up to $20^{\circ}$ is possible. This extended range of indication could be attributed to the firmly attached periarticular tissues and the presence of the Kirschner wire [4].

The purpose of this study was to evaluate our results with the distal metatarsal osteotomy with lateral displacement to correct hallux valgus deformities in adult patients.

\section{Material and Methods}

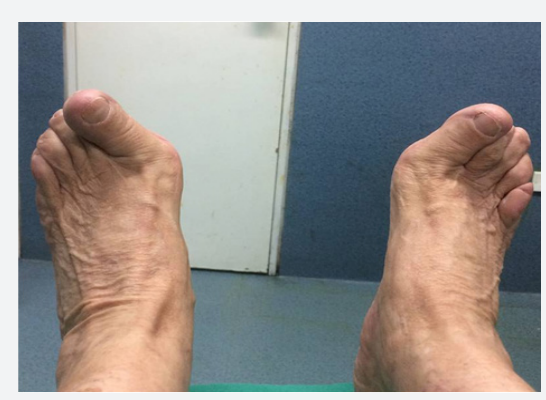

Figure 1: The photograph shows the feet of an 81-yearold woman with recurrent bilateral hallux valgus deformities previous surgery. 


\section{Orthopedics and Rheumatology Open Access Journal}

Between January 2012 and July 2016, distal osteotomy of the first metatarsal with lateral displacement has been used in the treatment of 10 patients with hallux valgus (Figure 1). Five patients had bilateral operation done, making up a total of 15 feet. Standing anteroposterior (AP) and Lateral X-rays were taken for radiological assessment (Figure 2).

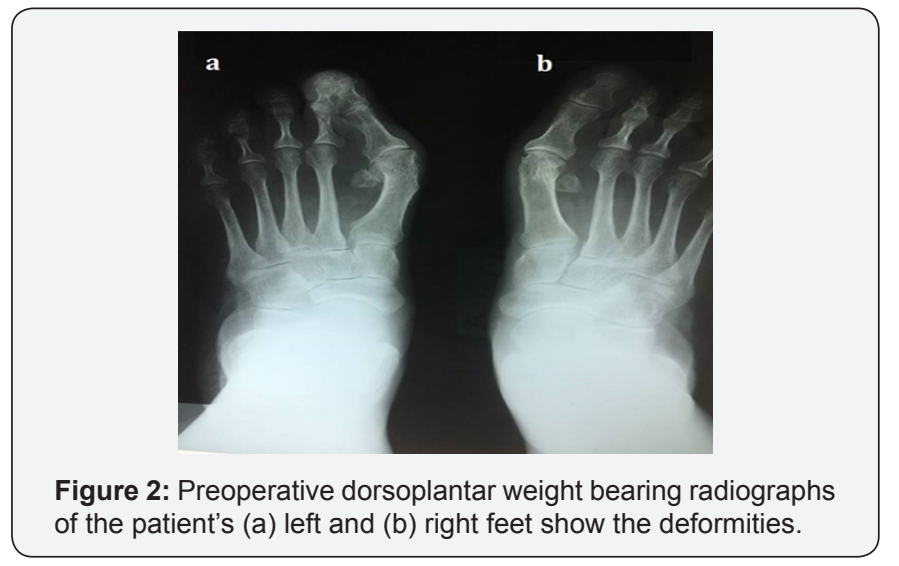

Criteria of inclusion consisted of a reducible hallux valgus deformity with the hallux valgus angle (HV angle) of $\leq 40^{\circ}$ and a first intermetatarsal (IM) angle of $\leq 20^{\circ}$.The technique was indicated even in cases of recurrent deformity except after previous Keller's procedure [5].

Patients with severe deformity and the intermetatarsal angle larger than $20^{\circ}$, severe degenerative arthritis or hallux rigidus, severe instability of the cuneometatarsal or metatarsophalangeal joint, and peripheral vascular disease or uncontrolled diabeteswere excluded [6,7].

\section{Surgical Technique}

The operation was performed under spinal or general anaesthesia. The surgical procedure was facilitated with the use a fluoroscopic image intensifier intraoperatively.

A medial skin incision centred at the intended osteotomy site of the distal part of the first metatarsal bone was made and sub-periosteal dissection was then performed to expose the metatarsal neck.

A 2.0-mm Kirschner wire (K-wire) was introduced firstly from the incision site in antegrade manner towards big toe pulp by tunneling in the soft tissue close to the proximal phalanx to exit near the medial nail fold and a transverse osteotomy was then performed at the metatarsal neck slightly proximal to the sesamoid bones using an oscillating micro-saw and completed laterally by using a small chisel. The distal bone segment was then laterally displaced with the help of a pair of small artery forceps and the osteotomy site was then stabilized by means of the K-wire, which was inserted retrograde up to the base of the medulla canal of the first metatarsal (Figure 2). Additional soft tissue release like modified Mcbride procedure was not performed in our series.
Skin wound was closed with fine suture after confirming the K-wire position radiologically (Figure 3A \& 3B). To maintain the hallux correction, a bandage was used to wrap aroundthe big toe and the bandage was also strapped around the second toe to give an additional control to the big toe rotation (Figure 4A). The distal tip of the K-wire was cut, bent, and capped.

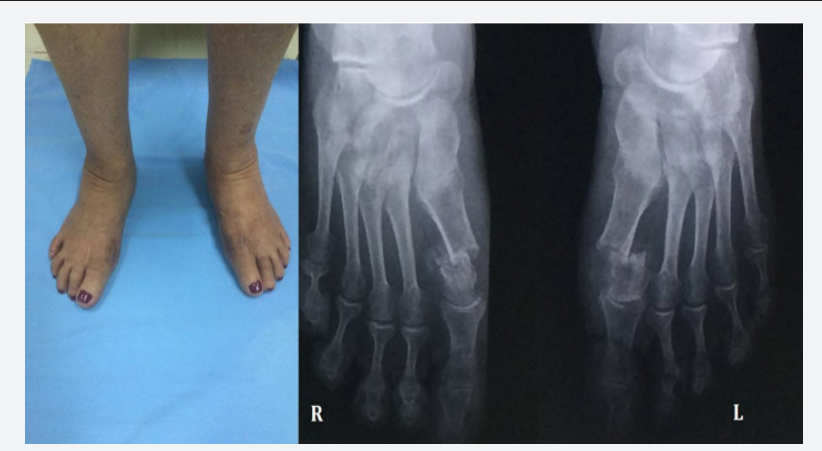

Figure 3: Clinical and radiological appearance after 6-month follow up.

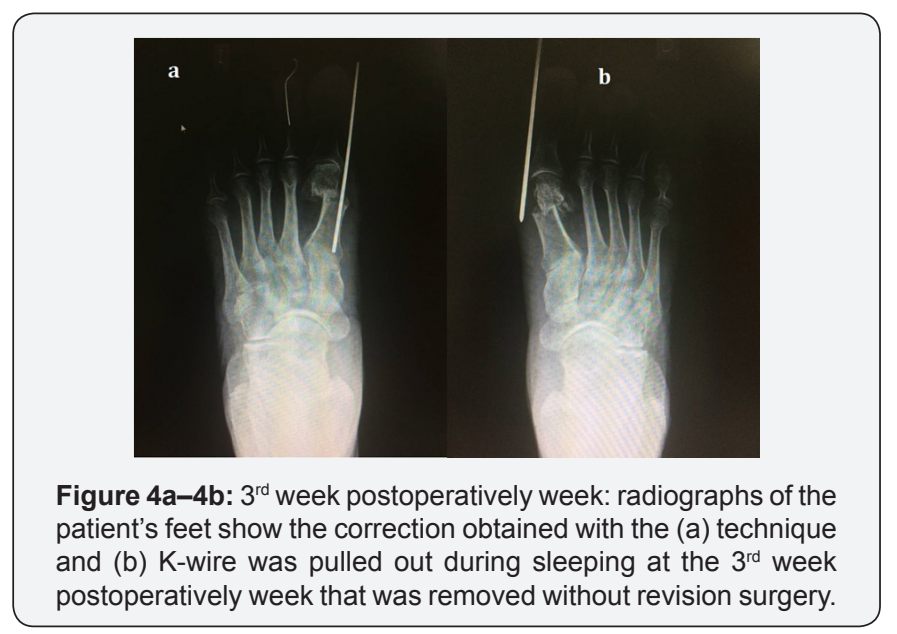

Postoperatively, heel walking was allowed in the first 2 weeks. When the pain was gradually reduced, forefoot partial weight-bearing walking was allowed. The K-wire was removed in 4-5 weeks, when clinical union had occurred. After the K-wire had been removed, full weight bearing walking exercise as tolerated was allowed. Normal shoe wear could be used 8-10 weeks after the operation.

\section{Clinical and Radiological Assessment}

The system proposed by the American Orthopaedic Foot and Ankle Society (AOFAS) was used to assess the result [8]. The scoring system ranged from 0 to 100 points, incorporating both subjective and objective factors into numerical scales to describe pain, functional capacity, and hallux alignment.

All the patients had pre- and postoperative standing anteroposterior (AP) and lateral radiographs of the foot taken. The HV angles, and first IM angle, were measured to assess the correction of the deformities. 


\section{Results}

For the bunion pain, all patients reported the disappearance or reduction of pain over the first metatarsal (MT) heads after the operation (Figure 3). The mean overall pain score was 36.7 points of the 40-point maximum on the AOFAS HalluxMetatarsophalangeal-Interphalangeal scale (Table 1).

Table 1: Functional results.

\begin{tabular}{|c|c|}
\hline Pain(40 points) & $36.7 \pm 4.9(30-40)$ \\
\hline Function (45 points) & $40.3 \pm 3.9(35-45)$ \\
\hline Alignment (15 points) & $13.6 \pm 2.9(8-15)$ \\
\hline Total (100 points) & $90.3 \pm 8.5(85-100)$ \\
\hline
\end{tabular}

The scoring for the functional capacity of the hallux (which assesses the activity limitation, footwear, metatarsophalangeal (MTP) joint motion, interphalangeal (IP) joint motion, joint stability, and callus) was averaged to 40.3 points (Table 1 ).

In terms of the hallux alignment, the overall mean score was 13.6 points. There was no patient with recurrence of hallux valgus (Table 1).

Using the AOFAS Hallux Scale (total 100 points), a mean improvement of total score from 56.06 points to 90.3 points was achieved in the 15 feet operated. Except one foot with fair result, all the rest of the patients (93.3\%) had excellent to good to excellent result (Table 1).

Radiologically, the mean $\mathrm{HV}$ angle improved from $32.1^{\circ}$ preoperatively to $13.7^{\circ}$ postoperatively. The mean first IM angle improved from $17.5^{\circ}$ to $7.9^{\circ}$ (Table 2).

Table 2: Radiological results.

\begin{tabular}{|c|c|c|}
\hline Angle & Preoperative & Postoperative \\
\hline HV & $32.1 \pm 5.8(20-40)$ & $13.7 \pm 4.7(4-20)$ \\
\hline First IM & $17.5 \pm 2.9(12-22)$ & $7.9 \pm(4-14)$ \\
\hline \multicolumn{2}{|c|}{ HV: Hallux Valgus IM: intermetatarsal } \\
\hline
\end{tabular}

\section{Complications}

No intraoperative complications occurred. There were 2 cases of mild pin tract infection, which resolved with a course of oral antibiotics. One patient had accidentally pulled out the K-wire during sleeping at the $3^{\text {rd }}$ week postoperatively that was removed without revision surgery (Figure 4). There were no instances of nonunion, malunion, or avascular necrosis of the metatarsal head.

\section{Discussion}

Hallux valgus a common foot deformity is defined when the angle formed by the bisection of $1^{\text {st }}$ metatarsal axis and proximal phalanx axis or hallux valgus angle (HVA) is $>15^{\circ}$ and the line joining bisection of the first and the second metatarsal axis known as first intermetatarsal angle (IMA)is more than $9^{\circ}$ [9].
First intermetatarsal angle (IMA) and the hallux valgus angle (HVA) are used to classify hallux valgus (HV) deformities and to evaluate the result of a surgical correction. The deformity is graded as mild with an IMA $<13^{\circ}$, moderate with IMA $13-20^{\circ}$, andsevere with IMA $>20^{\circ}$. Generally, HVA $>40^{\circ}$ is considered severe [10].

Although for a long time, bunion surgery had a reputation for being very painful with a lengthy recovery period more than 130 procedures have subsequently been described for correction $[11,12]$.

Surgical procedures for correction of hallux valgus include distal soft-tissue release, osteotomies through the base or head of the first metatarsal, arthrodesis of the metatarsocuneiform joint or metatarsophalangeal joint, excisional arthroplasty, and combined osteotomy and distal soft-tissue release. These procedures enable deformity correction, pain relief, and return to daily living [13-16].

Distal first metatarsal osteotomies traditionally have been indicated for correction of mild-to-moderate reducible deformity when the hallux valgus angle is as large as $40^{\circ}$, the intermetatarsal angle is as large as $20^{\circ}$, the metatarsophalangeal joint is either incongruent or congruent, or with modification of the Distal Metatarsal Articular Angle (DMAA), and if mild degenerative arthritis is present. The technique is indicated even in cases of recurrent deformity [5].

Specific contraindications of this technique are patients with severe deformity and the intermetatarsal angle larger than $20^{\circ}$, severe degenerative arthritis or hallux rigidus, severe instability of the cuneometatarsal or metatarsophalangeal joint, and in patients in whom a Keller's procedure unsuccessful $[6,7]$.

The distal metatarsal osteotomy in our study was a simple bony procedure without other specific soft tissue procedures. We did not perform bunion resection, or lateral release.The absence of lateral release explains the absence of hallux varus after surgery [6].

Our study involved 10 adult patients including 5 with bilateral hallux valgus deformity (15 feet) managed with distal metatarsal osteotomy and lateral displacement. The mean overall pain score was $36.7 \pm 4.9$ points of the 40 point maximum on the AOFAS, the scoring for the functional capacity of the hallux was averaged to 40.3 points, the overall mean score of the hallux alignment was 13.6 points, and the mean improvement of total score from 56.06 points to 90.3 points was achieved in the 15 feet operated. These results are comparable to other series that have reported satisfactory improvement in pain in $80-95 \%$ patients using other techniques [17-20].

\section{Conclusion}

Although the present paper is a retrospective review and included a small study population, we conclude that distal 
metatarsal osteotomy and lateral displacement with K-wire stabilization offered a reliable, reproducible, simple, safe, and cost-effective way of treating hallux valgus deformity.

\section{Statement of Informed Consent}

All study participants provided informed written consent prior to study enrollment.

\section{Statement of Human Rights}

All procedures followed were in accordance with the Helsinki Declaration of 1975, as revised in 2008. Informed consent was obtained from all patients for being included in the study.

\section{References}

1. Fraissler L, Konrads C, Hoberg M, Rudert M, Walcher M (2016) Treatment of hallux valgus deformity. EFORT Open Rev 1: 295-302.

2. Coughlin MJ, Jones CP (2007) Hallux valgus: demographics, etiology, and radiographic assessment. Foot Ankle Int 28(7): 759-777.

3. Hardy RH, Clapham JC (1951) Observations on hallux valgus; based on a controlled series. J Bone Joint Surg 33- B(3): 376-391.

4. Kuo CH, Huang PJ, Cheng YM et al. (1998) Modified Mitchell osteotomy for hallux valgus. Foot Ankle Int 19(9): 585- 589.

5. Oh IS, Kim MK, Lim KY, Bae JH (2007) Modified technique of distal metatarsal osteotomy for hallux valgus. Foot Ankle Int 28: 527-528.

6. Magnan B, Samaila E, Viola G, Bortolazzi P (2008) Minimally invasive retrocapital osteotomy of the first metatarsal in hallux valgus deformity. Oper Orthop Traumatol 20: 89-96.

7. S Giannini, F Vannini, C Faldini, R Bevoni, M Nanni, D Leonetti (2007) The minimally invasive hallux valgus correction (S.E.R.I.) Interact Surg 2(1): $17-23$

8. Kitaoka HB, Alexander IJ, Adelaar RS, Nunley JA, Myerson MS, et al. (1994) Clinical rating systems for the ankle hindfoot, midfoot, hallux, and lesser toes. Foot Ankle Int 15(7): 349-353.
9. Reverdin J (1881) On the outward deviation of great toe (hallux, valgus, bunions, balloons) and its surgical treatment. Trans Internat Med Congress 2: 408-412.

10. Robinson AHN, Limbers JP (2005) Modern concepts in the treatment of hallux valgus. J Bone Joint Surg 87-B: 1038-1045.

11. Cain TD, Boberg J, Ruch JA, et al. (1992) Distal metaphyseal osteotomies in hallux abducto valgus surgery. In: McGlamry ED, et al. (Eds.), Comprehensive textbook of foot surgery. ( $\left.2^{\text {nd }} e d n\right)$, Williams and Wilkins, Baltimore, p. 493-503.

12. Myerson MS (2000) Hallux valgus. In: Myerson MS (Ed), Foot and ankle disorders, Volume 2. Saunders, Philadelphia, USA, pp. 213-288.

13. De Lavigne C, Rasmont Q Hoang B (2011) Percutaneous double metatarsal osteotomy for correction of severe hallux valgus deformity. Acta Orthop Belg 77(4): 516-521.

14. Wulker N, Suckel A (2005) Metatarsal osteotomies for hallux valgus [in German]. Orthopade 34(8): 726; 728-734.

15. Panchbhavi VK, Rapley J, Trevino SG (2011) First web space soft tissue release in bunion surgery: functional outcomes of a new technique. Foot Ankle Int 32(3): 257-261.

16. Yamamoto K, Imakiire A, KatoriY, Masaoka T, Koizumi R (2005) Clinical results of modified Mitchell's osteotomy for hallux valgus augmented with oblique lesser metatarsal osteotomy. J Orthop Surg (Hong Kong) 13(3): 245-52.

17. Desjardins AL, Hajj C, Racine L, Fallaha M, Bornais S (1993) Mitchell osteotomy for treatment of hallux valgus. Ann Chir 47: 894-899.

18. Hardy RH, Clapham JC (1951) Observations on hallux valgus ; based on a controlled series. J Bone Joint Surg 33-B(3): 376-391.

19. Johnson JE, Clanton TO, Baxter DE, Gottlieb MS (1991) Comparison of chevron osteotomy and modified McBride bunionectomy for correction of mild to moderate hallux valgus deformity. Foot Ankle 12(2): 61-68.

20. Magnan B, Pezze L, Rossi N, Bartolozzi P (2005) Percutaneous distal metatarsal osteotomy for correction of hallux valgus. J Bone Joint Surg 87(6): 1191-1199.

\section{Your next submission with Juniper Publishers} will reach you the below assets

- Quality Editorial service

- Swift Peer Review

- Reprints availability

- E-prints Service

- Manuscript Podcast for convenient understanding

- Global attainment for your research

- Manuscript accessibility in different formats

( Pdf, E-pub, Full Text, Audio)

- Unceasing customer service

Track the below URL for one-step submission https://juniperpublishers.com/online-submission.php 